\title{
Two years follow up study of post placental insertion of IUCD during caesarean sections: safety, efficacy and complications
}

\author{
Dilpreet Kaur Pandher*, Shikha Rani, Poonam Goel
}

Department of Obstetrics and Gynecology, Government Medical College and Hospital, Chandigarh, India

Received: 27 December 2017

Accepted: 24 January 2018

\section{*Correspondence:}

Dr. Dilpreet Kaur Pandher,

E-mail: dr_dilpreet@yahoo.com

Copyright: (C) the author(s), publisher and licensee Medip Academy. This is an open-access article distributed under the terms of the Creative Commons Attribution Non-Commercial License, which permits unrestricted non-commercial use, distribution, and reproduction in any medium, provided the original work is properly cited.

\begin{abstract}
Background: The present study evaluates safety, efficacy, expulsion rate and complications of PPIUCD insertion in women undergoing caesarean section in a medical college for 2 years period.

Methods: This is a prospective cohort study done over a 2 year period. Total 185 patients undergoing caesarean section and fulfilling medical eligibility criteria for PPIUCD were enrolled in the study. The followup of these patients was done at 6 weeks, 6 months and 1-2 years.

Results: Thirteen patients (7\%) lost to follow up so final outcome analysis was done in 172 patients. The problems encountered were spontaneous expulsion in 4 patients, removal due to heavy menstrual flow in 13 patients, nonvisibility of threads in 4 patients, discharge per-vaginum in 1 patient and pain lower abdomen in 1 patient. Voluntary removal was done in 3 patients by 2 years who wished to conceive. The successful continuation rate came out to be $84.9 \%$ by 2 years. There was no failure reported in terms of intra-uterine or extra-uterine pregnancy and no increased risk of infection or perforation over the 2 years follow up.

Conclusions: Immediate post-placental IUCD insertion is safe and effective method of contraception with no need to wait for 6 weeks which thereby reduces unwanted pregnancy rates. Mild discomfort and the minor post procedure complaints are taken care of well in puerperium. Higher rate of expulsion can be taken care of by early follow-up with regular visits and offering other safe and effective method of contraception.
\end{abstract}

Keywords: Long acting reversible contraception, PPIUCD, Postpartum contraception, Postplacental CuT

\section{INTRODUCTION}

Globally, intrauterine devices (IUDs) are cited as the second most widely used contraceptive method according to a WHO study. ${ }^{1}$ The IUD recommended by WHO is CuT380A which got USFDA approval in 1984.

Post placental insertion of IUCD (PPIUCD) has been recommended by WHO to be safe, effective, reversible and immediate method of contraception. This is the time when parturient is highly motivated for effective contraception. In developing country like India where women are still not fortunate enough to get medical services easily, this is the time when most of them come in contact with the trained medical personnel.

Various studies have proved safety of IUCD when inserted post-placentally. It has good acceptability because of the safety and being reversible. ${ }^{2}$ WHO has approved IUCD use even in breast-feeding women since it has no effect on lactation, not even in terms of any increased copper in milk. ${ }^{3,4}$

PPIUCD overcomes the pain and anxiety of procedure as compared to the interval insertion. It is a good method of spacing and also beneficial for the females who don't 
want further child bearing as they can opt for sterilization once their child grows keeping in mind the higher rate of child mortality in developing countries.

However, PPIUCD insertion has few disadvantages also, most common being spontaneous expulsion which is comparatively less if insertion is done during caesarean section and can be further minimized in hands of adequately trained doctors and health care staff.

The present study was conducted to find out safety, efficacy, expulsion, complications, failure and successful continuation of PPIUCD (CuT 380A) inserted during caesarean section. The outcome was noted at 6 weeks, 6 months, 1 and 2 years.

\section{METHODS}

This prospective cohort study was done in Obstetrics and Gynecology department of government medical college and hospital, Chandigarh from April 2013 to March 2015. All the patients attending antenatal OPD and unbooked patients referred to labor room in emergency were made aware about the available facility of PPIUCD, motivated for it and their apprehensions were made clear. The women undergoing either elective or emergency caesarean section opted for PPIUCD or sterilization according to their wish for further child bearing. After finding fit for PPIUCD insertion according to medical eligibility criteria by WHO, total 185 patients who opted for intra-caesarean PPIUCD after obtaining informed written consent were recruited for the study.

The subjects excluded from the study were as per the WHO guidelines: premature rupture of membranes> 18 hours, unresolved postpartum hemorrhage, uterine malformation, features of maternal sepsis and chorioamnionitis.

$\mathrm{Cu} \mathrm{T} 380 \mathrm{~A}$ is available free of cost under supply by government of India in our institute. Within 10 minutes of placental expulsion and ruling out post partum haemorhage, CuT was placed at uterine fundus through the uterine incision. The threads of IUCD were not cut but kept in lower uterine segment (as per WHO recommendations).

Antibiotics were given to these patients as per the hospital protocol. Patients were followed up for 72 hours or till their stay in hospital to look for any immediate complication. At the time of discharge, patients were reenforced about the warning symptoms like pain, excessive bleeding per-vaginum or foul-smelling discharge per-vaginum. They were told to come immediately in such situation, otherwise to come for check-up at 6 weeks. At 6 weeks, if threads were visible then they were cut to about $2-2.5 \mathrm{~cm}$ length. If threads not visible, then ultrasonography was done to confirm localization of IUCD. If it was in place, patient was reassured, and no intervention was done. IUCD was removed if there was partial expulsion or any complication. Further follow up was done at 6 months, 1 and 2 years either in person or telephonically. The outcome was measured in terms of expulsion, any complication, indications of removal, failure rate and successful continuation rate.

\section{RESULTS}

During the study period, 5,110 patients who attended antenatal outpatient department were motivated for insertion of postpartum IUCD. Total number of patients delivered during this period was 12,657 including 4,914 caesarean sections. Out of these 4,914 caesarean section patients, $791(16 \%)$ opted for tubal sterilization and 185 $(3.8 \%)$ patients got intra-caesarean PPIUCD insertion done. These 185 patients were enrolled in the present study. At 6 weeks, 172 patients could be followed up, 13 patients were lost, could not be contacted by any means because of belonging to far off places, change of address or contact number; so were not included in the analysis of further outcome of the study.

Table 1: Demographic profile.

\begin{tabular}{|c|c|c|}
\hline Personal Factors & No. of patients & Percentage \\
\hline \multicolumn{3}{|l|}{ Age } \\
\hline$\leq 20$ & 2 & 1.2 \\
\hline $21-25$ & 76 & 44.2 \\
\hline $26-30$ & 72 & 41.8 \\
\hline $31-35$ & 22 & 12.8 \\
\hline \multicolumn{3}{|l|}{ Education } \\
\hline Uneducated & 19 & 11.0 \\
\hline Primary/ higher & $2 / 19$ & 12.2 \\
\hline Secondary & 60 & 34.9 \\
\hline Senior secondary & 42 & 24.4 \\
\hline Graduation & 21 & 12.2 \\
\hline Post graduation & 9 & 5.3 \\
\hline \multicolumn{3}{|c|}{ Monthly income INR } \\
\hline$\leq 5000$ & 45 & 26.2 \\
\hline $5000-10,000$ & 59 & 34.3 \\
\hline $10,000-50,000$ & 68 & 39.5 \\
\hline \multicolumn{3}{|c|}{ No. of living children including the present birth } \\
\hline One & 37 & 21.5 \\
\hline Two & 128 & 74.4 \\
\hline Three & 5 & 2.9 \\
\hline Four or more & 2 & 1.2 \\
\hline \multicolumn{3}{|c|}{ Reason for opting PPIUCD } \\
\hline No further pregnancy & 116 & 67.4 \\
\hline Spacing & 33 & 19.2 \\
\hline $\begin{array}{l}\text { Not sure for further } \\
\text { pregnancy }\end{array}$ & 23 & 13.4 \\
\hline \multicolumn{3}{|c|}{ Awareness about IUCD advantages } \\
\hline $\begin{array}{l}\text { Long term, effective } \\
\text { method }\end{array}$ & 31 & 18.0 \\
\hline Reversible & 8 & 4.6 \\
\hline Safe & 6 & 3.6 \\
\hline All the above & 127 & 73.8 \\
\hline
\end{tabular}


Baseline characters of 172 patients are shown in Table 1. Maximum number, $76(44.2 \%)$ of our patients were of age group 21-25 years, $60(34.9 \%)$ patients were secondary educated, $68(39.5 \%)$ patients belonged to 10,000- 50,000 per month income category. Majority of the patients i.e. $135(78.5 \%)$ had two or more living children after present child birth. $116(67.4 \%)$ patients didn't want any further child bearing but refused for sterilization at present. $127(73.8 \%)$ patients were aware of all the advantages of PPIUCD i.e. long term, safe, reversible and effective. 79 patients $(42.5 \%)$ out of these were booked patients in our institute and counseled during antenatal period for PPIUCD and 106 (57.5\%) patients were referred to our institute in emergency.

Table 2: Complications of PPIUCD on follow up at various periods.

\begin{tabular}{|llll|}
\hline $\begin{array}{l}\text { Complications } \\
\text { At } 6 \text { weeks }\end{array}$ & No. of cases & & Percentage \\
\hline $\begin{array}{l}\text { Spontaneous } \\
\text { expulsion }\end{array}$ & 4 & & 2.3 \\
\hline Strings not visible & 41 & 23.8 \\
\hline & $\begin{array}{l}\text { Reason for } \\
\text { removal }\end{array}$ & & \\
\hline 6 weeks-6 months & Menorrhagia & 9 & 5.2 \\
\hline & $\begin{array}{l}\text { Non-visible } \\
\text { strings }\end{array}$ & 4 & 2.3 \\
\hline & $\begin{array}{l}\text { Discharge P/V } \\
\text { Pain }\end{array}$ & 1 & 0.6 \\
\hline 6 months-1 year & $\begin{array}{l}\text { Persistent } \\
\text { menorrhagia }\end{array}$ & 4 & 0.6 \\
\hline 1 year-2 years & $\begin{array}{l}\text { Wish to } \\
\text { conceive }\end{array}$ & 3 & 1.8 \\
\hline
\end{tabular}

In all the patients of PPIUCD, there was no immediate complication during their hospital stay. At 6 weeks follow-up (Table 2), 4 patients gave history of expulsion of IUCD giving the expulsion rate to be $2.3 \%$. Nonvisualization of IUCD thread on per speculum examination was encountered in $41(23.8 \%)$ patients so transvaginal ultrasonography was done for IUCD localization. It was found to be in proper position in all these patients so were reassured.

At 6 months, $52(30.2 \%)$ patients reported to us and 120 $(69.8 \%)$ had follow up at the nearby hospitals as per their conveniences, who were contacted telephonically at the decided intervals. Fifteen patients got IUCD removal done by 6 months due to various reasons mentioned in Table 2. Three patients were still trying medical management for menorrhagia but got it removed before 1 year due to non-resolving problem. Maximum number i.e. $13(7.5 \%)$ patients got IUCD removal done due to menstrual complaints. By the end of 2 years follow-up, $149(86.6 \%)$ patients didn't have any complaint, but 3 patients got it removed for their wish to have next pregnancy giving the successful continuation rate of $84.9 \%$. None of our patient had failure of IUCD in terms of intrauterine or extrauterine pregnancy. The continuation rate at varied time periods is depicted in Table 3.

Table 3: Continuation rates at varied periods.

\begin{tabular}{|lll|}
\hline Continuation rate & No. of cases & Percentage \\
\hline 6 weeks & 168 & 97.7 \\
\hline 6 months & 153 & 89.0 \\
\hline 1 year & 149 & 86.6 \\
\hline 2 years & 146 & 84.9 \\
\hline
\end{tabular}

\section{DISCUSSION}

According to The Lancet study, the number of Indian women of reproductive age who are married or live with unmarried partners (in union) there is increase in use of modern contraceptive methods from $36.1 \%$ in 1990 to $52.2 \%$ in 2015 . In absolute numbers, the number of women using modern contraceptive methods has doubled, from 58 million in 1990, to 124 million in 2015. The unmet need for modern methods has fallen from $25.4 \%$ in 1990 , to $20.4 \%$ in 2015 , while the demand for family planning satisfied with modern methods has risen from $58.6 \%$ to $71.8 \%$ in the same period. ${ }^{5}$

Female sterilization and the IUD are the two most common methods used by married or in-union women worldwide. In 2015, 19 per cent of married or in-union women relied on female sterilization and 14 per cent used the IUD. Short-term methods are less common: 9, 8 and 5 per cent of women relied on the pills, male condoms and injectables respectively in 2015. Only 6 per cent of married or in-union women worldwide used rhythm or withdrawal. More than one in three married or in-union women globally use long-acting or permanent methods: namely, female and male sterilization, IUDs and implants. IUCD is the most widely used reversible method of contraception by females worldwide. ${ }^{6}$ According to a health survey published in 2008, incidence of non users of any form of contraceptive method was found to be $46 \%$ in India. ${ }^{7}$

In the present study, $16 \%$ patients undergoing caesarean section opted for sterilization as compared to only $3.8 \%$ patients choosing PPIUCD. Female sterilization is shown to be the most common method opted according to data by United Nations 2015, which shows $35.8 \%$ opting for female sterilization as compared to $1.8 \%$ using IUCD in India in $2008 .^{6}$

In the present study, maximum number of patients belonged to age group 21-25 years which is similar to the study by Kumar et al and Bansal et al.,9

In this study, majority (89\%) patients who accepted PPIUCD were educated to primary level or more than that. Acceptance was maximum (34.9\%) among secondary education patients and it was again reduced with higher education. Acceptance rate was $11 \%$ and $5.3 \%$ in uneducated and post graduate patients which 
were similar to the study done by Mishra who found $7.7 \%$ and $8.2 \%$ acceptance in these patients respectively. ${ }^{10}$ These findings confirm the importance of certain level of education for increased awareness and acceptance of post partum contraception which is long acting and reversible. Positive effect of education on contraceptive use has also been shown in a study done in Egypt by Safwat et al and in Zimbabwe by Thomas et al. ${ }^{11,12}$

$78.5 \%$ of our patients were multiparous which is similar to the study by Grimes et al where higher acceptance $(65.1 \%)$ was found in miltiparous clients but contrary to Bansal et al who had maximum number of primiparous patients. ${ }^{9,13}$ Present study emphasizes on the fact that our women who have completed their family are in need of long acting, immediate and safe contraceptive method which is reversible too till they decide about opting the permanent method.

After proper counselling, 127 (74\%) of our patients were aware of all its major advantages like long term, reversible, safe and effective method of contraception. Another 31 (18\%) were satisfied with its long term effective protection. In a study by Kumar et al, majority of women $(87.6 \%)$ reported the acceptance of PPIUCD as a contraceptive method due to the fact that it is a long acting method. Additionally, 22\% of women accepting a PPIUCD cited the free-of-charge services as one reason for choosing the method8. These findings suggest that women in our country with limited access to health care providers seek a method of contraception with long term protection. PPIUCD provides additional benefits too so has a good scope of acceptance in our population.

In the present study, $42.5 \%$ were booked in our institute and were counselled about the immediate post partum contraception in the antenatal period, the remainder of the patients $(57.5 \%)$ was made aware about the post partum contraception and availability of PPIUCD service at the time of hospitalization, prior to cesarean section whereas in the study done by Celen, $64 \%$ had received family planning counselling during antenatal period. ${ }^{14}$ This highlights the role of proper counselling in antenatal period as well as during labor since the parturient is highly motivated for the need of contraception during both these phases for the better and dedicated care of her new-born and her own health.

There was no immediate complication in the form of febrile illness, perforation or misplaced IUCD seen in our patients. Immediate postpartum insertion of IUCDs has been practiced in China since 1975. In a controlled trial comparing IUCD insertions at caesarean section with non-intervention controls, only a few complications were reported, and no difference was found in puerperal morbidity or infection. ${ }^{15}$

There was no case of PID in the present study; similar observation is made by Shukla et al. ${ }^{16}$ This could be due to careful and judicious selection of cases. Otherwise, there are various studies showing high prevalence of lower genital tract infections and sexually transmitted diseases in developing countries which may increase the risk of pelvic inflammation with the insertion of IUCD. ${ }^{17,18}$ Taking proper medical history, careful examination and use of prophylactic antibiotics can take care of this aspect.

Expulsion rate at 6 weeks was found to be $2.3 \%$ which is comparable to $3.6 \%$ expulsion rate at 6 weeks follow up reported by Kumar et al. ${ }^{8}$ Expulsion rates of PPIUCD insertion done during cesarean section has been reported from $0-5.7 \%$ in various studies. ${ }^{19-21}$ WHO-RHL study has emphasized that expulsion rate can be minimized by the better expertise of the surgeon. Thus, programmes should be conducted regularly to train the clinicians and special IUCD insertion kit should be provided to the health centers conducting deliveries. $^{22}$

According to Celen et al, removal rate for bleeding and other medical reasons was $5.3 \%$ and $10.6 \%$ at 6 and 12 months, which were comparable to incidence in our study of $8.7 \%$ and $11.0 \%$ respectively. ${ }^{14}$ Menorrhagia is the most common cause of removal in the present study which has been proven to be the most bothersome factor in various other studies., ${ }^{9,10}$

Non-visualisation of threads was encountered in $23.8 \%$ patients at 6 weeks but on ultrasonography IUCD was found to be in place in all of them. Missing thread rate was reported to be $8.7 \%$ and $16.2 \%$ at 6 weeks follow-up by Mishra $\mathrm{S}$ and Bansal et al respectively but none was found to have misplaced IUCD on ultrasonography. ${ }^{9,10}$

Lost to follow-up rate at first visit (6 weeks) in present study was $7 \%(13 / 185)$ which was quite low as compared to $21 \%$ in a study by Shukla et al. ${ }^{16}$ In study by Mishra, only $59.98 \%$ visited clinic, another $18.97 \%$ were followed up over phone and $23 \%$ were lost to follow up. ${ }^{9}$ At 6 months, only $30 \%$ of our patients came for followup to our institute, rest of the $70 \%$ visited nearby health facilities and was contacted telephonically. This emphasizes the importance of good communication means for the follow-up of patients.

Continuation rates is $89 \%, 86.6 \%$ and $85 \%$ at 6 months, 12 months and 2 years respectively in the present study, which was better than Celen et al who had continuation rate of $81.6 \%$ and $62 \%$ at 6 months and 12 months respectively. ${ }^{14}$ Mishra $\mathrm{S}$ reported $81.1 \%$ continuation rate at 6 months. ${ }^{10}$

In the present study, no case had failure of IUCD in the form of intra-uterine or extra-uterine pregnancy. $0.4 \%$ failure rate has been reported by Celen et al in PPIUCD patients. ${ }^{14}$ According to a WHO report, the twelve-month pregnancy rates reported in various studies ranged from 0.0 to $12.1 \% .^{22}$ 


\section{CONCLUSION}

Immediate post-placental IUCD insertion is safe and effective method of contraception with no need to wait for some definitive method of contraception till 6 weeks which thereby reduces unwanted pregnancy rates. Complications reported were excessive discharge pervaginum, pain lower abdomen, non- visibility of string and heavy menstrual bleeding which can be managed medically but necessitated removal in $12.8 \%$ patients. There was no failure of IUCD in terms of pregnancy and no increased risk of infection or perforation. Hence it is a safe and effective method of contraception.

Higher rate of expulsion can be taken care of by early follow-up with regular visits along with self examination by the patient to feel the strings and timely insertion of new IUCD or offering other safe and effective method of contraception.

\section{Funding: No funding sources}

Conflict of interest: None declared

Ethical approval: The study was approved by the Institutional Ethics Committee

\section{REFERENCES}

1. TCu380A Intrauterine Contraceptive Device (IUD) WHO/UNFPA Technical Specification and Prequalification Guidance 2016. Available at https://www.unfpa.org/sites/default/files/resourcepdf/TCu380A_IUD_WHO-

UNFPA_Tech._Spec_and_PQ_guidance_2016_final. pdf

2. Roberto Rivera, William Winfrey. UNDP/UNFPA/WHO/World Bank Special Programme of Research, Development and Research Training in Human Reproduction (HRP). External evaluation 2003-2007; Long-term safety and effectiveness of copper-releasing intrauterine devices: a case-study. World Health Organization 2008

3. Medical eligibility criteria for contraceptive use Intrauterine devices. 5th ed 2015. Available at http://apps.who.int/iris/bitstream/10665/181468/1/97 89241549158_eng.pdf. Accessed on 23 Dec 2017.

4. Rodrigues da Cunha AC, Doren JG, Cantuaria AA. Intrauterine device and maternal copper metabolism during lactation. Contraception. 2001;63(1):37-9.

5. Jin RN, Niamh C, John S, Yogender PG, Leontine A. Levels and trends in contraceptive prevalence, unmet need, and demand for family planning for 29 states and union territories in India: a modelling study using the Family Planning Estimation Tool. Lancet. 2017;5(3):e350-e358.

6. United Nations Population Division (UNPD) and Department of Economic and Social Affairs. World Contraceptive Use 2015. Available at http://www.un.org/en/development/desa/population/ publications/dataset/contraception/wcu2015.shtml.

Accessed on Nov 22, 2017.

7. Rutstein S. Further evidence of the effects of preceding birth intervals on neonatal, infant, and under-five-years mortality and nutritional status in developing countries: evidence from the demographic and health surveys. DHS Working Papers No. 41. Macro International;2008.

8. Somesh K, Reena S, Sudharsanam B, Elaine C, Kamlesh L, Richard S et al. Women's experience with postpartum intrauterine contraceptive device use in India. Reprod Health. 2014;11:32

9. Mamta B, Jyoti L, Khushbu P. Study of efficacy and complication of postpartum IUCD insertion at Govt. medical college, Bastar. Int $\mathrm{J}$ Reprod Contracept Obstet Gynecol. 2016 Dec;5(12):4128-31.

10. Sujnanendra M. Evaluation of safety, efficacy, and expulsion of post-placental and intra-Cesarean Insertion of Intrauterine Contraceptive Devices (PPIUCD). J Obstet Gynaecol India. 2014 Oct; 64(5):337-43.

11. Mohamed SA, Kamel MA, Shaaban OM, Salem HT. Acceptability for the use of postpartum intrauterine contraceptive devices: Assiut experience. Med Princ Pract. 2003;12(3):170-5.

12. Thomas D, Maluccio J. Fertility, contraceptive choice, and public policy in Zimbabwe. World Bank Econ Rev. 1996;10(1):189-222.

13. Grimes DA, Lopez LM, Schulz KF, Van Vliet HAAM, Stanwood NL. Immediate post-partum insertion of intrauterine devices. Cochrane Database Syst Rev. 2010;(5):CD003036.

14. Celen S, Sucak A, Yildiz Y, Danisman N. Immediate postplacental insertion of an intrauterine contraceptive device during caesarean section. Contraception. 2011;84:240-3.

15. $\mathrm{Xu} J X$, Reusché $\mathrm{C}$, Burdan A. Immediate postplacental insertion of the intrauterine device: a review of Chinese and the world's experiences. Adv Contracept. 1994; 10 (1):71-82.

16. Manju S, Sabuhi Q, Chandrawati. Post-placental intrauterine device insertion: A five year experience at a tertiary care centre in north India. Indian $\mathrm{J}$ Med Res. 2012;136:432-5.

17. Marai W. Lower genital tract infections among pregnant women: a review. East Africa Med J. 2001;78:581-5.

18. Kurewa NE, Mapingure MP, Munjoma MW, Chirenje MZ, Rusakaniko S, Stray-Pederson B. The burden and risk factors of sexually transmitted infections and reproductive tract infections among pregnant women in Zimbabwe. BMC Infect Dis. 2010;10:127.

19. Letti Müller AL, Lopes Ramos JG, Martins-Costa SH, Palma Dias RS, Valério EG, Hammes LS et al. Transvaginal ultrasonographic assessment of the expulsion rate of intrauterine devices inserted in the immediate postpartum period: a pilot study. Contraception. 2005;72(3):192-5. 
20. Raffat S, Azra J, Anila A. Immediate Postpartum Insertion of Intrauterine Device: An Ideal Method. JSOGP. 2015;5(1):34-9.

21. Chi IC, Su-Wen Z, Balogh S, Ng K. Post-cesarean section insertion of intrauterine devices. Am J Pub Health. 1984;74(11):1281-2.

22. Muthal-Rathore A. Immediate postpartum insertion for intrauterine devices: RHL commentary. The
WHO Reproductive Health Library; Geneva: World Health Organisation; 2010.

Cite this article as: Pandher DK, Rani S, Goel P. Two years follow up study of post placental insertion of IUCD during caesarean sections: safety, efficacy and complications. Int J Reprod Contracept Obstet Gynecol 2018;7:981-6. 